\title{
Parsonage-Turner Syndrome as a Rare Extrahepatic Complication of Hepatitis E Infection
}

\author{
Claude Ngah Njabom ${ }^{1}$, Allison Gilbert ${ }^{1}$, Edmond Brasseur ${ }^{1}$, Régine Zandona ${ }^{2}$, Alexandre Ghuysen², Vincent D'Orio ${ }^{2}$ \\ ${ }^{1}$ C.H.U. Liège, Emergency Department, site Notre Dame des Bruyères, Chênée, Belgium. \\ ${ }^{2}$ C.H.U. Liège, Emergency Department, site Sart Tilman, Angleur, Belgium
}

Received: $17 / 07 / 2019$

Accepted: $26 / 07 / 2019$

Published: $22 / 08 / 2019$

How to cite this article: Ngah Njabom C, Gilbert A, Brasseur E, Zandona R, Ghuysen A, D'Orio V. Parsonage-Turner syndrome as a rare extrahepatic complication of hepatitis E infection. EJCRIM 2019;6: doi:10.12890/2019_001208.

Conflicts of Interests: The Authors declare that there are no competing interest

This article is licensed under a Commons Attribution Non-Commercial 4.0 License

\section{ABSTRACT}

Parsonage-Turner syndrome, also known as neuralgic amyotrophy, is a rare disorder characterized by painful clinical manifestations mainly involving the upper limbs. This syndrome seems to be triggered, among other factors, by some viral infections, although its pathophysiology remains unclear. Moreover, it has rarely been related to hepatitis E virus infection. We report the case of a 33-year-old man who was diagnosed with Parsonage-Turner syndrome following acute hepatitis E infection.

\section{LEARNING POINTS}

- Parsonage-Turner syndrome is a painful and disabling condition.

- Hepatitis E infection can lead to extra-hepatic manifestations such as neurological complications.

- The association of Parsonage-Turner syndrome with hepatitis E infection is rare but some cases have been reported previously in the literature.

\section{KEYWORDS}

Parsonage-Turner syndrome, hepatitis E, neuralgic amyotrophy

\section{CASE DESCRIPTION}

A 33-year-old man was admitted to the emergency department with a 1-week history of disabling shoulder pain. The patient had no previous significant medical conditions and had been travelling in Spain when the painful syndrome began. He first attended a Spanish hospital but $x$-rays and biological findings were negative. When he returned from Spain, paresthesia and paresis involving the two upper limbs developed and he was admitted to the nearest emergency department. Clinical examination revealed bilateral paresis of the upper limbs with bilateral scapula alata, areflexia of both upper limbs, and hypoesthesia in the right circumflex nerve territory and in the left radial nerve territory. Biological findings only revealed moderate hepatic cytolysis. CT of the cervical spine did not demonstrate any pathological findings. Electroneuromyography showed evidence of bilateral peripheral motor nerve involvement with sensory axonal loss in the territories of the lateral ante-brachial cutaneous nerve. The diagnosis of Parsonage-Turner syndrome (PTS) was made. Aetiological assessment revealed positive hepatitis E antibodies. Treatment with intravenous corticoids was administered. The patient underwent rehabilitation and gradually recovered over a few months. 


\section{DISCUSSION}

PTS is an acute neuropathy mainly affecting the brachial plexus or its branches and is characterized by non-specific and painful clinical manifestations ${ }^{[1]}$. This syndrome was first described in 1948 by Parsonage and Turner who suggested the term 'neuralgic amyotrophy'. Many other names have since been proposed but neuralgic amyotrophy seems the most appropriate ${ }^{[1]}$.

Clinical manifestations are predominantly painful and disabling symptoms of the shoulders and arms, sometimes irradiating to the neck. Disease onset is sudden, but manifestations can last for weeks before the diagnosis is made. Pain is usually followed by muscle weakness, amyotrophy, paralysis and sensory abnormalities ${ }^{[2]}$. The symptoms are mainly unilateral but can be bilateral in $16 \%$ of cases $^{[2]}$.

The aetiology of this disease is still unclear. Some precipitating events (immunization, infection, surgery, trauma, etc.) seem to trigger the syndrome but its pathophysiology remains uncertain. Infection is frequently described as a contributing factor since up to $52 \%$ of PTS cases follow an initial infectious disease $\mathrm{e}^{[3]}$. The main pathophysiological hypothesis is an immune-mediated process ${ }^{[3]}$.

Hepatitis E virus (HEV) infection has been associated with extra-hepatic manifestations, and particularly with neurological complications in approximatively $5.5-7.5 \%$ of patients ${ }^{[4,5]}$. PTS seems to be related to $\mathrm{HEV}$ infection and in such cases tends to present more frequently with bilateral and asymmetric manifestations. Consequently, the discovery of hepatic cytolysis in a patient with PTS suggests an acute HEV infection since $10 \%$ of patients with PTS have positive HEV antibodies ${ }^{[5,6]}$.

The diagnosis of Parsonage-Turner syndrome is essentially made on the basis of typical anamnestic and clinical features along with electroneuromyographic findings. Sometimes, MRI of the cervical spine and brachial plexus is helpful[ ${ }^{[7]}$.

First-line treatment is based on analgesia together with anti-inflammatory drugs and other co-analgesics. Immunotherapy with intravenous immunoglobulins has been administered in some cases, while other patients have been treated with intravenous corticosteroids. However, there are currently no specific guidelines based on reliable controlled trials ${ }^{[8]}$.

The outcome is mostly favourable, although in some cases functional recovery is incomplete even after a long period of rehabilitation. However, reports in the literature indicate that $80-90 \%$ of patients fully recover ${ }^{[9]}$.

\section{CONCLUSION}

Parsonage-Turner syndrome is a rare condition with painful and disabling clinical manifestations and a lengthy recovery. This case report highlights the importance of considering the association of neuralgic amyotrophy with hepatitis E infection in patients with PTS presenting with hepatic cytolysis.

\section{REFERENCES}

1. Seror P. Neuralgic amyotrophy. An update. Joint Bone Spine 2017;84:153-158.

2. Tjoumakaris FP, Anakwenze OA, Kancherla V, Pulos N. Neuralgic amyotrophy (Parsonage-Turner syndrome). J Am Acad Orthop Surg 2012;20(7):443-449.

3. Smith C, Bevelaqua AC. Challenging pain syndromes: Parsonage-Turner syndrome. Phys Med Rehabil Clin N Am 2014;25:265-277.

4. Dartevel A, Colombe B, Bosseray A, Larrat S, Sarrot-Reynauld F, Belbezier A, et al. Hepatitis E and neuralgic amyotrophy: five cases and review of the literature. J Clin Virol 2015;69:156-164.

5. Avila JD, Lacomis D, Lam EM. Neuralgic amyotrophy associated with hepatitis E virus infection: first case in the United States. J Clin Neuromuscul Dis 2016;18(2):96-100.

6. Bisciglia M, Van den Bergh P, Duprez T, Kabamba BM, Ivanoiu A. Neuralgic amyotrophy associated with hepatitis E virus (HEV) infection: a case report. Acta Neurol Belg 2017;117(2):555-557.

7. Feinberg JH, Radecki J. Parsonage-Turner syndrome. HSS J 2010;6(2):199-205.

8. Van Eijk JJ, Groothuis JT, Van Alfen N. Neuralgic amyotrophy: an update on diagnosis, pathophysiology and treatment. Muscle Nerve 2016;53:337-350.

9. Feinberg JH, Nguyen ET, Boachie-Adjei K, Gribbin C, Lee SK, Daluiski A, et al. The electrodiagnostic natural history of Parsonage-Turner syndrome. Muscle Nerve 2017;56:737743. 